\title{
Transparência do Orçamento Público Municipal: desenvolvimento de uma ferramenta (aplicativo) digital capaz de monitorar em tempo real o Legislativo Municipal de São Leopoldo (RS)
}

Angelica Denise Klein ${ }^{1}$

Resumo: O artigo tem como tema a transparência, objetivando-se analisar a transparência das despesas do Legislativo Municipal por meio da implantação de um aplicativo. Para tanto, o objetivo específico é examinar as características da subsidiariedade e a autonomia local. A justificativa para pesquisar tal questão deu-se em razão da necessidade de tornar transparentes as despesas do Legislativo Municipal, aproximando o cidadão da Câmara Municipal, a par disso, a problemática incidente é verificar se é possível a implantação do aplicativo, tendo como base o projeto-piloto da PUCRS: "Meu Deputado", para monitoramento das despesas do Legislativo Municipal? A metodologia de pesquisa se consubstanciou na análise dos sítios eletrônicos da Câmara Municipal de São Leopoldo e da Câmara dos Deputados, e o método de procedimento utilizado neste trabalho consistiu na abordagem bibliográfica e documental para investigar o tema com sua fundamentação teórica, justificando seus limites e contribuições. Como resultado, verificou-se que, não obstante a existência do Portal Transparência junto aos sítios da Prefeitura Municipal e da Câmara Municipal, estes são deficitários e imprecisos, de modo que o aplicativo seria de vital importância para possibilitar o monitoramento, em tempo real, e também um facilitador para aproximar o cidadão, para controlar as despesas públicas e monitorar/cobrar o Legislativo Municipal dos projetos elaborados e deliberados.

Palavras-chave: Aplicativo. Princípio da subsidiariedade. Princípio da transparência.

Abstract: The article has the theme Transparency, aiming at the release of the expenses of the Municipal Legislative through the implementation of an application. To that end, specific use is a feature of subsidiarity and local autonomy. The justification for obtaining such a purpose was the reason to become public as a municipal legislative issue, approaching the citizen of the City Council, and a problematic incident is a pilot project of PUCRS: "MeuDeputado", for monitoring of the expenses of the Municipal Legislative? Methodology of analysis and data analysis of the São Leopoldo City Hall and the Chamber of Deputies, and the key word used in the work is to do the bibliographic and documentary analysis to investigate the theme with its justification, justifying its limits and. As a result, it was verified, despite the existence of the Transparency Portal next to the City Hall and City Hall sites, these are deficient and inaccurate, so the application would be of vital importance to allow real-time monitoring and also a facilitator to approach the citizen, to control the public expenses and to monitor / charge the Municipal Legislative of the elaborated and deliberate projects.

Keywords: App. Principle of subsidiarity. Principle of transparency.

\footnotetext{
${ }^{1}$ Doutoranda em Diversidade Cultural e Inclusão Social pela Universidade FEEVALE (Novo Hamburgo/RS). angelica.dk@hotmail.com.
} 


\section{Introdução}

O artigo tem como tema a transparência e o objetivo é analisar a transparência das despesas do legislativo municipal por meio da implantação de um aplicativo. Para tanto, os objetivos específicos são examinar as características da subsidiariedade e a autonomia do poder local.

A justificativa para pesquisar tal questão deu-se em razão da necessidade de tornar transparentes as despesas do legislativo municipal, aproximando o cidadão da Câmara Municipal, a par disso, a problemática incidente é verificar se é possível a implantação do aplicativo, tendo como base o projeto-piloto da PUCRS, para monitoramento das despesas do legislativo municipal?

A metodologia de pesquisa se consubstanciará em uma análise dos sítios eletrônicos da Câmara Municipal de São Leopoldo e da Câmara dos Deputados, e o método de procedimento utilizado neste trabalho consistirá em uma abordagem bibliográfica e documental para investigar o tema com sua fundamentação teórica, justificando seus limites e contribuições. O procedimento de coleta de dados será a análise dos sítios oficiais.

Para tanto, o trabalho foi estruturado em três pontos, sendo que no primeiro momento objetiva-se examinar as características do princípio da subsidiariedade, em seguida pretende-se delinear acerca do princípio da transparência, seus limites e contribuições para âmbito municipal e, por fim a análise recairá sobre a possibilidade de implantação de um aplicativo para monitoramento das despesas do legislativo municipal, tomando como base a Câmara Municipal de São Leopoldo, a partir do modelo aplicado na Câmara dos Deputados.

\section{Princípio da Subsidiariedade: Conceitos e Características}

A análise do princípio da subsidiariedade tem como base o autor José Alfredo de Oliveira Baracho, que analisou o conceito e a evolução de tal princípio no ano de 1996.

A Constituição Federal previu os direitos fundamentais. Para Gimenez (2016), os direitos fundamentais são aqueles que correspondem à manutenção dos pressupostos elementares de uma vida na liberdade na dignidade humana. Para tanto, os direitos fundamentais foram classificados em: direitos individuais (artigo 5. direitos fundamentais do homem como cidadão), direitos à nacionalidade (artigo 12), direitos políticos (artigos 14 ao 17), direitos sociais (artigos 60 e 193), direitos coletivos (artigo 5--direitos fundamentais do homem em uma coletividade), direitos solidários (artigos 30 e 225- direitos fundamentais do gênero humano). (SILVA, 2014).

Para definir as competências, a Constituição Federal considerou as competências comuns pertencentes à União, aos Estados, ao Distrito Federal e aos Municípios, conforme artigo 23 da CF, transcrito abaixo: 
Art. 23. É competência comum da União, dos Estados, do Distrito Federal e dos Municípios:

I- zelar pela guarda da Constituição, das leis e das instituições democráticas e conservar o patrimônio público;

II- cuidar da saúde e assistência pública, da proteção e garantia das pessoas portadoras de deficiência;

III- proteger os documentos, as obras e outros bens de valor histórico, artístico e cultural, os monumentos, as paisagens naturais notáveis e os sítios arqueológicos;

IV- impedir a evasão, a destruição e a descaracterização de obras de arte e de outros bens de valor histórico, artístico ou cultural;

V- proporcionar os meios de acesso à cultura, à educação, à ciência, à tecnologia, à pesquisa e à inovação; (Redação dada pela Emenda Constitucional no 85, de 2015) VI- proteger o meio ambiente e combater a poluição em qualquer de suas formas; $\mathrm{VII}$ - preservar as florestas, a fauna e a flora;

VIII - fomentar a produção agropecuária e organizar o abastecimento alimentar;

IX- promover programas de construção de moradias e a melhoria das condições habitacionais e de saneamento básico;

$\mathrm{X}$ - combater as causas da pobreza e os fatores de marginalização, promovendo a integração social dos setores desfavorecidos;

$\mathrm{XI}$ - registrar, acompanhar e fiscalizar as concessões de direitos de pesquisa e exploração de recursos hídricos e minerais em seus territórios;

XII- estabelecer e implantar política de educação para a segurança do trânsito.

Parágrafo único. Leis complementares fixarão normas para a cooperação entre a União e os Estados, o Distrito Federal e os Municípios, tendo em vista o equilíbrio do desenvolvimento e do bem-estar em âmbito nacional. (Redação dada pela Emenda Constitucional no 53, de 2006) (BRASIL, 1988).

A Emenda Constitucional no 85, de 26 de fevereiro de 2015 dispôs acerca da possibilidade de "proporcionar os meios de acesso à cultura, à educação, à ciência, à tecnologia, à pesquisa e à inovação" (BRASIL. 2015). É dentro deste contexto que se insere a proposta do aplicativo para monitoramento das despesas do legislativo municipal, que será explanado na sequência.

Salienta-se, outrossim, que não obstante a Constituição Federal de 1988 não explicitar o princípio da subsidiariedade, implicitamente admite-se sua presença constitucional a partir do artigo 23 , que dispõe da competência comum entre União, Estados, Distrito Federal e Municípios (que seria a definição jurídica do princípio da subsidiariedade) e do artigo 30, que traz um rol meramente exemplificativo das competências privativas dos municípios.

Art. 30. Compete aos Municípios:

I - legislar sobre assuntos de interesse local;

II - suplementar a legislação federal e a estadual no que couber;

III - instituir e arrecadar os tributos de sua competência, bem como aplicar suas rendas, sem prejuízo da obrigatoriedade de prestar contas e publicar balancetes nos prazos fixados em lei;

IV - criar, organizar e suprimir distritos, observada a legislação estadual;

$\mathrm{V}$ - organizar e prestar, diretamente ou sob regime de concessão ou permissão, os serviços públicos de interesse local, incluído o de transporte coletivo, que tem caráter essencial;

VI - manter, com a cooperação técnica e financeira da União e do Estado, programas de educação infantil e de ensino fundamental;(Redação dada pela Emenda Constitucional no 53, de 2006) 
VII - prestar, com a cooperação técnica e financeira da União e do Estado, serviços de atendimento à saúde da população;

VIII - promover, no que couber, adequado ordenamento territorial, mediante planejamento e controle do uso, do parcelamento e da ocupação do solo urbano;

IX - promover a proteção do patrimônio histórico-cultural local, observada a legislação e a ação fiscalizadora federal e estadual (BRASIL, 1988).

Em termos de autonomia frente à União e ao Estado, Roque Antônio Carazza (1994, p.46) pondera que a autonomia dos Municípios é ínfima:

Os Municípios não influem, nem muito menos decidem, no Estado Federal. Dito de routro modo, não participam da formação da vontade jurídica nacional. Realmente, não integram o Congresso, já que não possuem representantes nem no Senado Federal e nem da Câmara dos Deputados. Como se isso não bastasse, a autonomia não é uma cláusula pétrea. O Congresso Nacional no exercício de seu poder constituinte derivado, pode, querendo, aprovar emenda constitucional que venha a diminuir ou mesmo a eliminar a autonomia dos Municípios.

Objetivando-se analisar a partir de um conceito, Margarida Salema D'Oliveira Martins (2003, p. 500) sublinha que, "a subsidiariedade é concebida mais como uma colaboração que se organiza no seio da sociedade do que como um auxílio acordado pelo estado à sociedade". Tal análise decorre da subsidiariedade horizontal, organizada entre os cidadãos.

[...] permanece, contudo imutável, aquele solene princípio de filosofia social: assim como é injusto subtrair aos indivíduos o que eles podem efetuar com a própria iniciativa e trabalho, para confiar à comunidade, do mesmo modo, passar para uma sociedade maior e mais elevada o que comunidades menores e inferiores podem realizar, é uma injustiça, um grave dano e perturbação da boa ordem social (MARTINS, 2003, p. 501).

O princípio da subsidiariedade não objetiva, contudo, delegar todas as tarefas à comunidade, visa repassar à comunidade as tarefas possíveis de serem realizadas e resolvidas pelos cidadãos do espaço local que reconhecem a dinâmica do município, suas limitações e suas potencialidades.

A importância do Município, sob o escopo do espaço local ganhou força, para aproximar o cidadão do meio em que vive. Para Ricardo Hermany (2007, p. 264-265) o espaço local "mostra-se mais viável na possibilidade de representação dos cidadãos, inclusive em virtude do mencionado sentimento de pertencimento, em função das peculiaridades e identidades culturais".

As contribuições positivas do poder local em detrimento a globalização são estratégias que favorecem a concretização da cidadania,

o poder local - ou também como é comumente denominado, "espaço local" - é um processo maior de comunicação e controle social, que surge após avaliações, discussões e articulações em âmbito global. Essa redefinição do espaço local enquanto esfera de menor complexidade contribui para retornar a centralidade ao cidadão, muitas vezes contraposto ao distanciamento da globalização excludente. 
Espaço local é um meio de concretização dos princípios constitucionais, porém também com limitações e restrições constitucionais, uma vez que o fortalecimento do poder local pode ser contraditório, mas é, sem dúvida alguma, estratégia de cidadania, manutenção do controle social sobre decisões públicas e concretização da Constituição Federal (NUNES; STURZA, 2011, p. 29-30).

No entanto, Hermany (2012) pondera que, deve-se ter cautela na adoção e na finalidade do princípio da subsidiariedade, pois se mostra "incompatível com posturas extremas, seja com adoção de uma municipalização exclusiva das políticas públicas ou postura centralizadora com o desvio hermenêutico dos conceitos de eficiência e economicidade" (HERMANY, 2012, p. 80).

Para Barracho (1996, p. 19) a atuação dos atores sociais e políticos decorrentes das decisões públicas a partir do espaço local revelam-se mais favoráveis, gerando confiança e credibilidade, pois as "relações entre cidadãos e autoridades devem iniciar-se nos municípios, tendo em vista o conhecimento recíproco, facilitando o diagnóstico dos problemas sociais e a participação motivada e responsável dos grupos sociais na solução dos problemas".

A participação da comunidade nas decisões políticas e sociais apoia-se na necessidade da informação e da transparência. Para que os cidadãos tomem ciência de programas sociais ativos, a informação governamental deve ser clara e precisa e, na mesma medida, para que os dados sejam visíveis, a fim de possibilitar a pesquisa e também a fiscalização, faz-se necessária a transparência.

Assim, na sequência o estudo trará pontos importantes da Lei no 12.527, de 18 de novembro de 2011, que regulou o acesso a informações previsto no inciso XXXIII do artigo 5ำ, no inciso II do § 3어 do artigo 37 e no § 2o do artigo 216 da Constituição Federal; altera a Lei no 8.112, de 11 de dezembro de 1990; revoga a Lei no 11.111, de 05 de maio de 2005 e dispositivos da Lei no 8.159, de 08 de janeiro de 1991.

\section{Transparência dos Dados: Mecanismo Necessário para Empoderar o Cidadão no Espaço Local}

Desde 2011, os entes federados- Municípios, Estados, Distrito Federal e a União- são obrigados, sob a égide da Lei no 12.527/2011, a disponibilizarem as despesas e os orçamentos públicos, tornando-nos transparentes e acessíveis a todos. Além dos entes federados, o parágrafo único do artigo 1o previu a subordinação dos órgãos públicos integrantes da administração direta dos Poderes Executivo e Legislativo, incluindo as Cortes de Contas, Judiciário e Ministério Público, bem como as autarquias, fundações públicas, empresas públicas, sociedades de economia mista e demais entidades controladas direta ou indiretamente pela União, Estados, Distrito Federal e Municípios (BRASIL, 2011).

Em relação às entidades privadas, sem fins lucrativos que porventura recebam do ente público recursos financeiros, a publicidade "refere-se à parcela dos recursos públicos recebidos e à sua destinação, sem prejuízo das prestações de contas a que estejam legalmente obrigadas" (artigo 2ํ). Partindo-se de tal norte, o direito fundamental de acesso à informação, deve obedecer aos princípios da administração públicalegalidade, impessoalidade, moralidade, publicidade e eficiência - amparados pelas diretrizes de: I - 
observância da publicidade como preceito geral e do sigilo como exceção; II - divulgação de informações de interesse público, independentemente de solicitações; III - utilização de meios de comunicação viabilizados pela tecnologia da informação; IV - fomento ao desenvolvimento da cultura de transparência na administração pública e $V$ - desenvolvimento do controle social da administração pública.

Em termos de controle de políticas públicas, a transparência dos dados mostra-se de extrema importância, vital para evitar desvio da finalidade proposta.

"Conhecimento é poder", afirmou Francis Bacon nos idos de 1605 . A aceitação
desta máxima implica no reconhecimento de que o acesso ao poder está
diretamente relacionado ao acesso a informações. Difundir o conhecimento
significa compartilhar e democratizar o poder. Restringi-lo, por sua vez, resulta na
concentração do poder nas mãos daqueles que detêm o acesso a informações
(ANDI, 2009).

A internet mostra-se com meio útil e potencialmente expansivo, vez que aproxima o cidadão das informações, rompendo barreiras físicas e geográficas (LÉVY, 1996). Umas das diretrizes previstas pela legislação infraconstitucional regulamenta a utilização de meios de comunicação viabilizados pela tecnologia da informação. Neste contexto, Ricardo Hermany e luri Bolesina analisaram que através da internet é possível o controle das atividades públicas, além do controle social do Estado.

O uso político da internet pelos cidadãos é uma das formas de realizar, de modo facilitado - pois sem as amarras temporais e espaciais -, o controle social das atividades públicas. Essa propriedade que a internet possui possibilita reverter pois ela já havia sido invertida - a lógica política à sua forma anterior, mais voltada ao cidadão. Passa-se do controle social pelo Estado para o controle social do Estado. (HERMANY, BOLESINA, 2015, p. 67).

Os referidos autores complementaram sublinhando que a "Lei de Acesso à Informação brasileira representa um passo importante para o controle social e a participação política, ao empoderar os cidadãos com direitos e ferramentas para o acesso e utilização da informação" (HERMANY, BOLESINA, 2015, p. 75).

A contribuição da tecnologia para a transparência dos dados além de aproximar os cidadãos também possibilita o controle social e político, nestes termos, Ricardo Hermany e Diogo Frantz $(2015$, p. 12) ressaltaram que: 


\begin{abstract}
As tecnologias de informação e de comunicação, de fato, abriram oportunidades para transformar o relacionamento entre governo, cidadãos, sociedade civil organizada e empresas, contribuindo para alcançar a boa governança, especialmente na dimensão transparência. A tecnologia da informação auxilia a implementação das políticas públicas e também favorece o monitoramento da implementação, o controle da política e a avaliação dos resultados, em termos da aplicação dos recursos, mas, principalmente, na efetividade das políticas implementadas. Também, o uso da tecnologia pode fazer o trabalho de suporte de comunicação, de workgroup, e viabilizar a eficiência interna de processos - como processos de compra, viagens de servidores, recursos humanos, controle de receitas e despesas, acompanhamento do planejamento governamental, e outros. Ainda, em e-administração, se pode incluir a integração de políticas públicas entre as várias esferas de governo.
\end{abstract}

A legislação infraconstitucional além de assegurar a concretização do direito fundamental de acesso à informação, também determina o dever dos órgãos e entidades a disponibilizarem as informações de interesse coletivo.

Dentre os artigos, o artigo 5o pontua o dever do Estado em oferecer, mediante procedimentos objetivos e ágeis, de forma transparente, clara e em linguagem de fácil compreensão. E, com base nesta lei, amparados nos artigos e, em razão da previsão de obrigatoriedade também do legislativo municipal, o recorte que se dará no tópico seguinte abordará a possibilidade de implantação de aplicativo, para monitoramento, em tempo real das despesas dos vereadores que compõem a Câmara Municipal de São Leopoldo.

\title{
4 Aplicativo para Monitorar em Tempo Real as Despesas do Legislativo Municipal de São Leopoldo
}

O município de São Leopoldo foi fundado em 1824, no Estado do Rio Grande do Sul. É considerado berço da colonização alemã no Brasil. Os imigrantes chegaram em meados de 1824.

Do grupo, 33 eram da religião evangélica e seis católicos; na ocasião foram instalados na Feitoria, espaço rurícola. Em 1961, através da Lei Estadual no 4.203, houve o desmembramento do município de São Leopoldo e do distrito de Sapucaia do Sul. Este se tornou município em 1963. (IBGE, 2013).

Situa-se na região metropolitana, cerca de $30 \mathrm{~km}$ da Capital do Estado - Porto Alegre. Tem uma população de 229.678 habitantes, estimativa realizada no ano de 2016. Com uma área territorial de 102,km2 (SÃO LEOPOLDO, 2016).

Em termos de transparência, em 2012, adveio o Decreto no 7.099, regulamentando, no âmbito da administração direta e indireta do Poder Executivo de São Leopoldo "os procedimentos para a garantia do acesso à informação pública e para prestá-la às pessoas naturais e jurídicas com eficiência, efetividade, agilidade, objetividade, transparência, de forma clara e em linguagem de fácil compreensão" (SÃO LEOPOLDO, 2016a).

O Legislativo Municipal, por sua vez, categorizou a transparência em três ferramentas- Transparência Administrativa, Transparência Fiscal e Transparência Legislativa. 
Considerando que o escopo do artigo pretende analisar a possibilidade de implantação de aplicativo para monitoramento, em tempo real, das despesas do legislativo municipal, a exemplo da ferramenta empregada junto a Câmara dos Deputados.

O aplicativo 'Meu Deputado' foi criado pelos alunos do Brazilian Education Program for iOS Development (BEPID), programa para capacitação em tecnologias iOS oferecido pela PUCRS, através da Faculdade de Informática e pelo Instituto Eldorado,

O app, que está disponível na App Store, mostra os gastos dos deputados federais mensalmente. Nele, é possível identificar onde foi investida a verba destinada aos políticos, como divulgação, combustível, passagens áreas, hospedagem, entre outros. "A nossa ideia era fazer um aplicativo que facilitasse a visualização das informações", afirma Claudio da Silva Dias Junior, um dos desenvolvedores. Os integrantes do grupo que ajudou a elaborar e executar o projeto são Anderson Kloss (Ciência da Computação - PUCRS), Claudio da Silva Dias Junior (Ciência da Computação - PUCRS), Felipe Vielitz (Jogos Digitais - Unisinos), Gianfranco Meneguz (Sistemas para Internet - IFRS), e Kévin Cardoso de Sá (Jogos Digitais Unisinos). A ideia surgiu após os alunos serem incitados a desenvolver um aplicativo que compreendesse uma problemática da sociedade. A política, então, foi o caminho escolhido. $\mathrm{O}$ app permite que o usuário acesse as notas fiscais referentes aos seus gastos. Uma das opções é enviar um e-mail- já existe um texto base pronto- questionando sobre o destino dos recursos públicos. Segundo Junior, informação é o que o povo brasileiro precisa para mudar o País (PUCRS, 2016).

O aplicativo encontra-se disponível, para ser baixado por meio do sítio https://itunes.apple.com/br/app/meu-deputado/id1041114377?mt=8, permitindo que os usuários dos aparelhos com sistemas iPhone, iPad e iPod touch possam monitorar, em tempo real, as despesas diárias do Deputado Federal selecionado. O ponto negativo é a restrição dos sistemas, não aceitando que sejam baixados nos smartphone, com o sistema operacional Android, que representam cerca de $86,2 \%$ dos aparelhos em atividade no território brasileiro, ao passo que o sistema operacional iOS alcançou cerca de $12,9 \%$.

O monitoramento é de extrema importância para possibilitar ao cidadão o acompanhamento das despesas e do orçamento público. Em sede municipal, o aplicativo, para smartphone, permitiria aos leopoldenses acompanhá-los.

Conforme consulta ao sítio da Câmara Municipal, o relatório das "diárias", para o ano de 2016 foi elaborado em 02.08.2016, contendo apenas a rubrica das "diárias no país" e os gastos nos meses de fevereiro, abril, maio e julho. As colunas de valores de fevereiro e julho são idênticas. Inexistindo dados capazes para verificar qual a origem da diária ou ainda qual o vereador que a utilizou e para qual finalidade. 
Cámara Municipal de Sáo Leopoddo

Página 1 de 1

0201201616 16:23:58

Relaçao - Nensal por Rubricas Órginos filtro)

Exercicio de 2016

Cámara Municipal de Säo Leopoldo

Órgäa: 01 CAMARAMUNCIPAL

\begin{tabular}{|c|c|c|c|c|c|c|c|c|c|c|c|c|c|}
\hline \multirow[t]{2}{*}{ Codloor } & \multicolumn{13}{|c|}{ Valor Empenhado / Llquldaco / Pape } \\
\hline & Janotio & Fverediro & Marpo & Abril & Malo & Juatho & Juhn & Apocto & Selembro & Oatubere & Novermbero & Desembroro & ACUMULADO \\
\hline \multirow{3}{*}{ 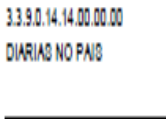 } & 0,00 & 4808,10 & 0000 & 10010,08 & 16554,56 & 0,00 & 4886.6 & 0,00 & 0,00 & 0,00 & 0,00 & 0,00 & $3,61,44$ \\
\hline & 0,00 & 4808,10 & 0000 & 7837,44 & 18827,20 & 0,00 & 48864 & 0,00 & 0,00 & 0,00 & 0,00 & 0,00 & $3.65,44$ \\
\hline & 0,00 & 4608,10 & 0000 & 7837,44 & 18827,20 & 0,00 & 4886.6 & 0,00 & 0,00 & 0,00 & 0,00 & 0,00 & $3,46,1,4$ \\
\hline \multirow[t]{3}{*}{ Total Oragso } & 0,00 & 408610 & 0000 & 10010008 & 1665466 & 0,00 & 48964 & 0,00 & 0,00 & 0,00 & 0,000 & 0,00 & $3,61,44$ \\
\hline & 0,00 & 4608,10 & 0000 & 7837,44 & 18887,20 & 0,000 & 48986 & 0,00 & 0,00 & 0,00 & 0,00 & 0,00 & $3,651,44$ \\
\hline & 0,00 & 468060 & 0000 & 7837,44 & 18827,20 & 0,00 & 48886.6 & 0,00 & 0,00 & 0,00 & 0,00 & 0,00 & $3,65,44$ \\
\hline \multirow{3}{*}{ TOTAL OERRL . EXERCICIO } & 0,00 & $4.808,60$ & 000 & 10010,08 & 16654,66 & 0,00 & 48886. & 0,00 & 0,00 & 0,00 & 0,00 & 0,00 & $3,61,4$ \\
\hline & 0,00 & 408060 & 000 & $1837,4,4$ & 18887,20 & 0,000 & 4886 & 0,00 & 0,00 & 0,00 & 0,00 & 0,00 & $3.61,44$ \\
\hline & 0,00 & 480860 & 0000 & 7837,44 & 18827,20 & 0,000 & 48886 & 0,00 & 0,000 & 0,00 & 0,000 & 0,00 & $3 ., 61,44$ \\
\hline
\end{tabular}

Fonte: Câmara Municipal, 2016.

Em relação às despesas com os "Veículos Oficiais", verifica-se a existência das datas e das notas de empenhos, não permitindo examinar, p.ex., qual a origem do veículo? Qual o vereador que a utilizou? Qual a finalidade? Porque o Posto escolhido foi o Posto de Combustíveis do Airton Ltda., localizado na Avenida Feitoria, distante do Centro do Centro do Município, em aproximadamente $5 \mathrm{~km}$ ? 


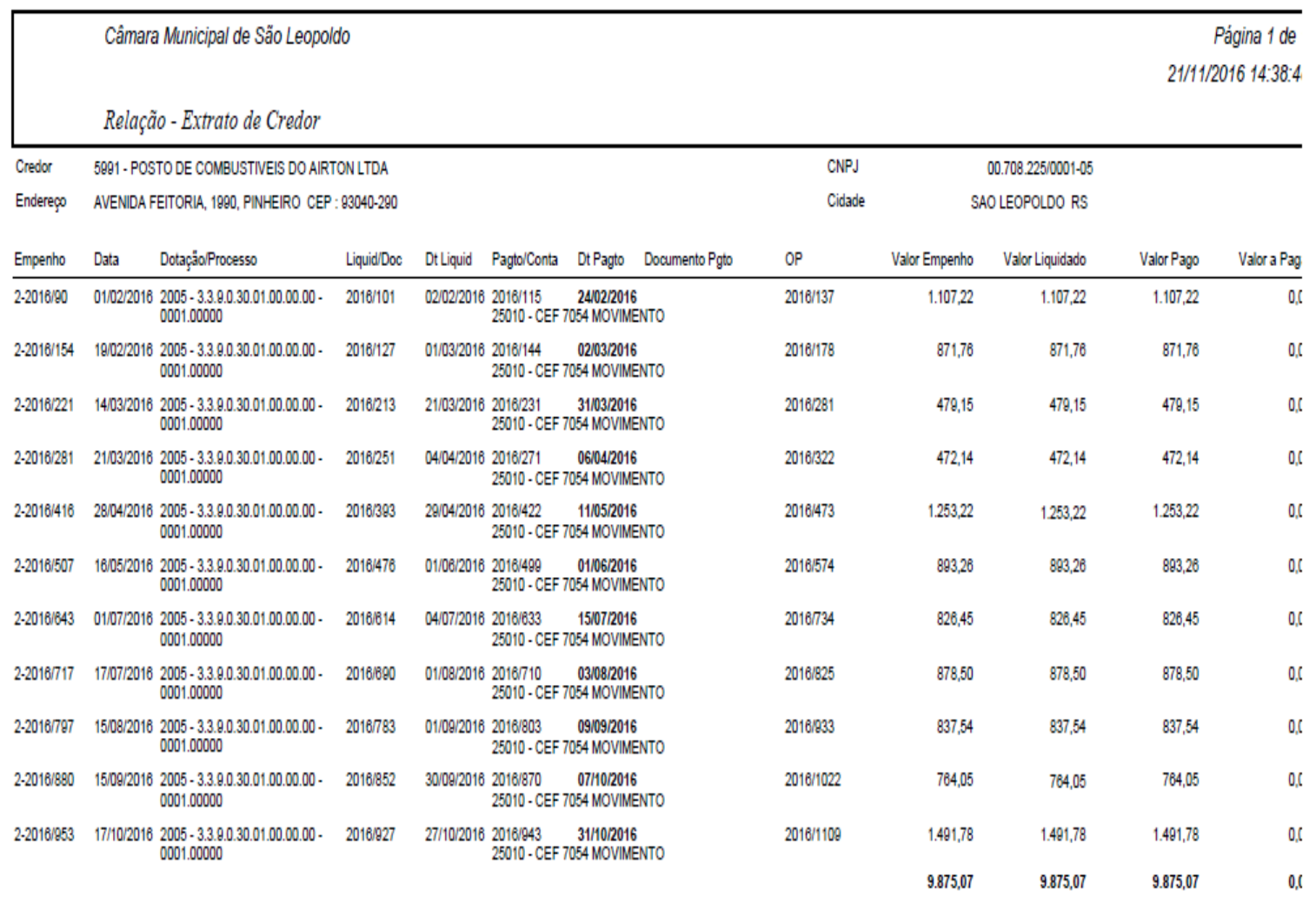

Fonte: CÂMARA MUNICIPAL, 2016.

As despesas do orçamento do Legislativo Municipal até outubro de 2016 alcançaram $\mathrm{R} \$$ 9.115.415,43. As despesas mais acentuadas são: "vencimentos e vantagens fixas- pessoal civil" com aproximadamente $\mathrm{R} \$ 5.151 .170,23$ e, o título "outros serviços de terceirospessoa jurídica", com dois valores, sendo que um refere-se ao valor de aproximadamente $\mathrm{R} \$$ 4.350,00 e outro R\$1.753.875,44. (CÂMARA MUNICIPAL, 2016).

Inexistem dados identificando a origem de tais despesas ou ainda quem são os destinatários, contrariando, portanto, a Lei da Transparência (BRASIL, 2011).

Do trabalho que é realizado pelos vereadores, verifica-se que estes possuem cerca de quatro pautas por mês. Tomando como exemplo o mês de novembro de 2016, examina-se que as plenárias foram as seguintes: 
Resultado da Sessão de 03/11/2016

Exp. 1620 - Processo Legislativo Especial n.e 001/16 - Mesa Diretora - "Parecer do Tribunal de Contas do Estado do Rio Grande do Sul referente ao Processo de Contas dos Administradores do Executivo Municipal de São Leopoldo no exercício de 2008". Documento Anexado por maioria

Exp. 1711 - Decreto Legislativo n.o 001/16 - Comissão de Finanças, Orçamento, Economia e Planejamento - "Aprova as contas do Prefeito Municipal no exercício de 2008". Aprovado por Maioria. Contrários: Iara Cardoso, Brasil Oliveira, Cláudio Giacomini, e Carlos Szulcsewsk (CÂMARA MUNICIPAL, 2016a)

A primeira pauta examinou as contas do Executivo de 2008, ou seja, decorridos oito anos, o Legislativo aprovou as contas dos Administradores e do Prefeito Municipal.

As pautas informando, suscintamente, acerca das autorizações do Poder Executivo para abertura de crédito especial não informam ao cidadão, de forma transparente para qual finalidade refere-se o orçamento, vez que a redução dos orçamentos, que podem ser identificados refere-se à saúde e a educação, a exemplo da redução do orçamento do Programa Saúde da Família, que é um programa do Governo Federal.

Em 2011, a Controladoria Geral da União (CGU) emitiu a cartilha intitulada "O vereador e a fiscalização dos recursos públicos municipais", com a finalidade de incentivar o legislativo a realizar a fiscalização e o controle dos gastos públicos. Tal iniciativa também poderia ser direcionada ao cidadão, tendo como ferramenta a transparência dos dados, das despesas e do orçamento público (CGU, 2009).

Visando combater a corrupção na administração pública, o Ministério da Justiça (MJ), com apoio do Ministério do Planejamento Orçamento e Gestão (MP) e da Controladoria Geral da União (CGU) promoveram o concurso como "Estratégia Nacional de Combate à Corrupção e à Lavagem de Dinheiro (ENCCLA). O objetivo da iniciativa é fortalecer o combate à corrupção, por meio da ampliação da participação do cidadão na fiscalização das políticas públicas executadas pelo Governo Federal". O aplicativo vencedor foi da Paraíba, sob a denominação de "Hackathon - Participação no Combate à Corrupção" (PLANEJAMENTO, 2016).

A importância da instantaneidade da informação através do aplicativo impulsionou o Tribunal de Contas dos Municípios (TCM), do Estado do Ceará, o qual lançou recentemente o Portal da Transparência dos Municípios para smartphones e tablets. A iniciativa do TCM 
aproxima o cidadão dos municípios, uma vez que permite examinar as contas dos municípios pertencentes ao Estado do Ceará.

\begin{abstract}
Com uma plataforma de fácil navegação, o novo serviço permite acesso a uma série de dados que integram as prestações de contas dos 184 municípios cearenses, como receitas, despesas, licitações e estrutura administrativa. Além disso, possibilita consultar documentos como o Relatório de Acompanhamento Gerencial (Reage) e verificar a data em que o ente fez a última entrega de prestação de contas ao TCM. (TCM, 2016)
\end{abstract}

O Senado Federal veiculou em seu sítio a inicialização da página www.prefeitura.gov.br, possibilitando que os cidadãos fiscalizassem, por meio da internet, a destinação e a utilização do erário pelos prefeitos. Entretanto, apesar da inciativa, ao acessar o endereço acima, a página informa que "não foi localizada".

Salienta-se, outrossim, que existe o Portal Transparência, disponível no link http://www.portaldatransparencia.gov.br, permitindo ao cidadão acessar as despesas, os serviços e demais informações. Fazendo-se uma pesquisa pelo município de São Leopoldo,

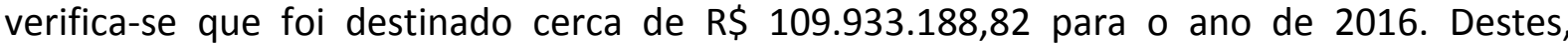
destacam-se as rubricas para a FUNDEB, no valor de $\mathrm{R} \$ 16.629 .134,14$ e os recursos destinados a Atenção à saúde da população para procedimentos em média e alta complexidade, no valor de $\mathrm{R} \$ 3.23 .921 .152,26$, muito embora o Município seja responsável tão-somente pelos atendimentos básicos.

Acessando-se o sítio da Prefeitura Municipal de São Leopoldo, no link destinado aos "Recursos", verifica-se que, ao solicitar "auxílio da União" a página informa que inexiste recurso: 


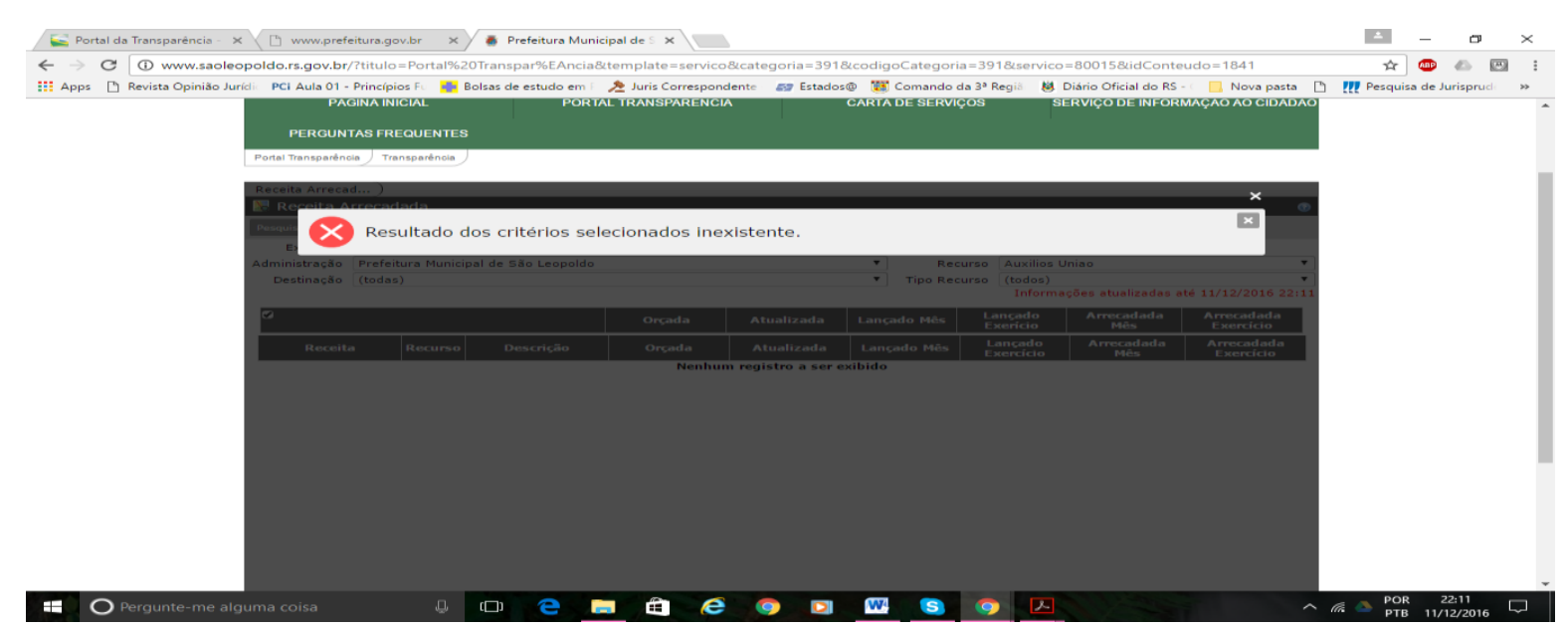

Fonte: Portal Transparência, São Leopoldo, 2016.

Entretanto, ao solicitar o recurso "FUNDEB", nota-se que o valor arrecadado é potencialmente superior ao destinado pela União: $\mathrm{R} \$ 96.629 .668,41$ ao passo que o recurso recebido pela União foi $\mathrm{R} \$ 16.629 .134,14$.

A arrecadação total do município, em 2016, foi de $\mathrm{R} \$ 586.862 .230,14$, frente às

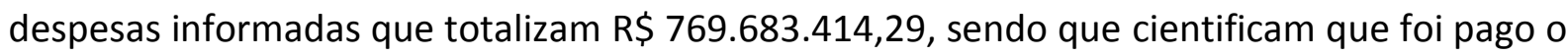
equivalente a $\mathrm{R} \$ 586.862 .230,14$. (SÃO LEOPOLDO, 2016)

Nota-se que tanto a Câmara Municipal (Legislativo) quanto a Prefeitura Municipal (Executivo), não obstante possuírem o Portal Transparência trazem rubricas que não são claras, contrariando o entendimento constante na legislação infraconstitucional.

E, além disso, a Câmara Municipal traz dados gerais de despesas "gerais", impossibilitando o controle por parte dos cidadãos.

Assim, o aplicativo, em tempo real, além de aproximar o cidadão do Legislativo, seria um facilitador para combater possíveis desvios do erário, e, quiçá, tentativas corruptivas, pois, como visto acima, o Portal Transparência do Governo informa a destinação de recursos ao Município, mas ao acessar a página do Município, tal dado não se encontra visível.

O aplicativo também impulsionaria que o Legislativo Municipal pautasse mais projetos, considerados relevantes para o Município, como aumento do número de creches municipais, para acomodar as crianças de baixa renda em detrimento da solicitação "do serviço de limpeza e conservação da Praça do Imigrante em frente ao prédio da Câmara Municipal". Tal responsabilidade é da Secretaria de Serviços Urbanos do Executivo Municipal. Assim, tem-se como indevido utilizar uma pauta de plenária, com 13 vereadores, 
para deliberaram sobre a limpeza de uma praça. Cada vereador recebeu, em 2016, o subsídio mensal equivalente a $\mathrm{R} \$ \mathbf{8 . 1 1 2 , 6 8}$. A despesa com a Câmara Municipal, no ano de 2016, foi de aproximadamente $\mathrm{R} \$ 11.900 .000,00$.

Assim, não é suficiente constar no Portal Transparência, os dados carecem estar de forma clara e precisa, amplamente, compreensível aos cidadãos. Ao empregar o aplicativo acessível ao cidadão, à aproximação com as decisões, com as despesas e com o orçamento público seria facilitado, de modo a viabilizar que o cidadão exerça sua cidadania de forma efetiva.

O desenvolvimento de iniciativas locais capazes de promover a inserção dos cidadãos viabilizaria o exercício do controle das despesas públicas, pois o cidadão exerce um papel fundamental no município em que vive, devendo exercitá-lo em todos os momentos, não se restringindo ao momento do voto. $\mathrm{O}$ acompanhamento das propostas de governo municipal, bem como o orçamento público e, sobretudo a aderência das despesas às políticas públicas reguladas, tornariam o cidadão mais presente e controlador do erário que deve ser gasto em programas, projetos e obras públicas, não se permitindo desvios de dinheiro público.

O acompanhamento em tempo real da presença do vereador, cumprindo o seu papel junto a Câmara Municipal e, o monitoramento dos orçamentos e despesas públicas, quiçá, diminuíram as patologias corruptivas, porquanto os cidadãos teriam elementos para questioná-los.

No momento, a fiscalização é realizada pelo Tribunal de Constas do Estado e pelo Ministério Público Estadual, tendo o cidadão um papel restrito. Assim, ao falar em desenvolvimento regional, perfilhando-se os desafios para nosso século, deve-se partir do local para o global, analisando-se se as políticas públicas possuem a destinação correta, reduzindo-se as despesas com obras inacabadas e ampliação de políticas públicas consideradas básicas para o desenvolvimento da criança, adolescente, gestante e idoso.

\section{Considerações finais}

O artigo buscou analisar a transparência das despesas do legislativo municipal por meio da implantação de um aplicativo. A justificativa para pesquisar tal questão deu-se em razão da necessidade de tornar transparentes as despesas do legislativo municipal, 
aproximando o cidadão da Câmara Municipal, a par disso, a problemática incidente foi verificar a viabilidade de implantação do aplicativo, tendo como base o projeto-piloto da PUCRS, para monitoramento das despesas do legislativo municipal.

Neste sentido, acredita-se que o aplicativo, além de aproximar o cidadão também possibilitaria o controle das despesas do erário, evitando, assim, patologia corruptivas, pois os dados seriam veiculados em tempo real.

O trabalho restou ancorado no princípio da subsidiariedade, para examinar a importância do espaço local e da autonomia do poder local. Os referenciais teóricos empregados corroboraram com a importância do espaço local para os cidadãos.

Além de promover a autonomia dos cidadãos também se faz necessário permitir o acesso às informações, para tanto, a Lei no 12.527/2011 adveio sob o escopo de garantir, constitucionalmente, que a todos seja assegurado o acesso às informações, as quais devem ser repassadas de forma transparente, clara e compreensível.

Para facilitar o acesso, restou proposto, a exemplo do projeto-piloto "Meu Deputado", a implantação do aplicativo junto ao Legislativo Municipal de São Leopoldo. Para tanto, inicialmente, foram apresentados dados relativos ao município, no tocante as questões geográficas e habitacionais. Em seguida foram explorados os sítios da Prefeitura Municipal e da Câmara Municipal de São Leopoldo. Ambas possuem o Portal Transparência, entretanto, carecem de informações claras, precisas e compreensivas.

Assim, a estratégia do aplicativo, para monitorar as despesas e os orçamentos públicos, além das pautas dos projetos seria vital para articular a efetividade, a objetividade e, precipuamente, a clareza dos dados, uma vez que assim como o Portal Transparência, não é suficiente ter alguns dados, estes precisam ser claros, transparentes e compreensíveis aos cidadãos.

\section{Referências}

ANDI, Acesso à informação e controle social das políticas públicas; coordenado por Guilherme Canela e Solano Nascimento. Brasília, DF: ANDI. Artigo 19, 2009. Disponível em: <http://www6.ufcspa.edu.br/_static/acesso-a-informacao-e-controle-social-das-politicaspublicas.pdf. >. Acesso em: 10 dez. 2016. 
BARACHO, José Alfredo de Oliveira. O princípio da subsidiariedade. Conceito e evolução. Rio de Janeiro: Forense, 1996.

Constituição da República Federativa do Brasil de 1988. Disponível em:

<https://www.planalto.gov.br/ccivil_03/constituicao/constituicaocompilado.htm>. Acesso em: 10 dez. 2016.

Emenda Constitucional no 85, de 26 de fevereiro de 2015. Altera e adiciona

dispositivos na Constituição Federal para atualizar o tratamento das atividades de ciência, tecnologia e inovação. Disponível em: <http://www.planalto.gov.br/ccivil_03/

Constituicao/Emendas/Emc/emc85.htm>. Acesso em: 10 dez. 2016.

Lei no 12.527, de 18 de novembro de 2011. Regula o acesso a informações previsto no inciso XXXIII do art. 5으, no inciso II do § 3ㅇ do art. 37 e no $\S 200$ art. 216 da Constituição Federal; altera a Lei $n=8.112$, de 11 de dezembro de 1990; revoga a Lei $n=11.111$, de 5 de maio de 2005, e dispositivos da Lei no 8.159, de 8 de janeiro de 1991; e dá outras providências. Disponível em:< http://www.planalto.gov.br/ccivil_03/_ato20112014/2011/lei/l12527.htm>. Acesso em: 10 dez. 2016.

CÂMARA MUNICIPAL. Pautas. Disponível em:

<https://legis.camarasaoleopoldo.rs.gov.br/?sec=npautas> Acesso em: $10 \mathrm{dez}$. 2016.a

Portal. Disponível em: <https://www.camarasaoleopoldo.rs.gov.br/portal/.> Acesso em: 10 dez. 2016.

CARRAZZA, Roque Antônio. Curso de direito constitucional tributário. 6. ed. São Paulo: Malheiros, 1994.

CGU. O vereador e a fiscalização dos recursos públicos municipais / Presidência da República, Controladoria-Geral da União- Brasília: CGU, 2009. Disponível em: < http://www.cgu.gov.br/cartilhavereadores> Acesso em: 10 dez. 2016.

Cidadãos fiscalizam pela internet como prefeitos aplicam dinheiro público. Disponível em:<http://www12.senado.leg.br/noticias/materias/2016/10/04/cidadaos-fiscalizam-pelainternet-como-prefeitos-aplicam-dinheiro-publico/>. Acesso em: 10 dez.2016.

GIMENEZ, Charlise Paula Colet . O papel do terceiro mediador na política pública brasileira de tratamento de conflitos- Resolução no 125 de 29 de novembro de 2010 do Conselho

Nacional de Justiça brasileiro- à luz da experiência do modelo do tribunal de múltiplas portas do distrito de Colúmbia, Estados Unidos da América. Tese doutoramento. UNISC: Santa Cruz do Sul, 2016. Disponível em:

<http://repositorio.unisc.br/jspui/bitstream/11624/1105/1/Charlise\%20Paula\%20Colet\%20 Gimenez\%20TESE.pdf.> Acesso em: 03 dez.2016. 
Governo premia aplicativo que identifica padrões diferenciados de gastos em municípios. Disponível em:<http://www.planejamento.gov.br/assuntos/logistica-e-tecnologia-dainformacao/noticias/governo-premia-aplicativo-que-identifica-padroes-diferenciados-degastos-em-municipios.> Acesso em: $10 \mathrm{dez} .2016$.

HERMANY, Ricardo. (Re)Discutindo o espaço local: uma abordagem a partir do direito social de Gurvitch. Santa Cruz do Sul: Edunisc, 2007.

. Município na Constituição: poder local no constitucionalismo Luso-Brasileiro.

Curitiba: Juruá, 2012.

; BOLESINA, luri. Revista Jurídica da Presidência Brasília v. 17 n. 111 Fev./Maio 2015

p. 63-85. Disponível em: <https://revistajuridica.presidencia.gov.br/index.php/saj/article/ view/1108.> Acesso em: 10 dez. 2016.

; FRANTZ, Diogo. Audiências públicas eletrônicas como instrumento de controle social e estratégia de combate às patologias corruptivas. Disponível em:<https://online.unisc.br/acadnet/anais/index.php/sidspp/article/viewFile/13228/2272.> Acesso em: 10 dez. 2016.

IGGE. Disponível em:

<http://cidades.ibge.gov.br/painel/historico.php?lang=\&codmun=431870\&search=riogrande-do-sul|sao-leopoldo|infograficos:-historico.> Acesso em: 10 dez. 2016.

LÉVY, Pierre. O que é virtual. Tradução de Paulo Neves. São Paulo: Editora 34, 1996.

MARTINS, Margarida Salema D'Oliveira. O princípio da subsidiariedade em perspectiva jurídico- política. Coimbra: Coimbra editora, 2003.

NUNES, Josiane Borghetti Antonelo; STURZA, Janaína Machado. O espaço local e a descentralização da saúde: elementos basilares para a (re)democratização do estado e conquista da cidadania. Revista USCS - Direito - ano X - n. 21 - jul./dez. 2011. Disponível em: <http://seer.uscs.edu.br/index.php/revista_direito/article/view/1632. >. Acesso em: 10 dez. 2016.

PUCRS. Aplicativo permite vigiar os gastos dos deputados federais. Meu Deputado foi desenvolvido no programa BEPiD. . Disponível em: < http://www.pucrs.br/blog/aplicativopermite-vigiar-os-gastos-dos-deputados-federais/>. Acesso em: 10 dez. 2016.

SÃO LEOPOLDO. Decreto no 7.099, de 18 de maio de 2012. Disponível em: <http://www.saoleopoldo.rs.gov.br/?titulo=Portal\%20Transpar\%EAncia\&template=hotSite\& categoria=391\&codigoCategoria=391\&tipoConteudo=INCLUDE_MOSTRA_CONTEUDO\&idCo nteudo=210. $>$ Acesso em: 10 dez. 2016. a

Portal do Município. Disponível em: http://www.saoleopoldo.rs.gov.br/:>.Acesso em: 10 dez. 2016. 
SILVA, José Afonso da. Curso de direito constitucional positivo. 37. ed. São Paulo: 2014.

TCM. Portal da transparência é lançado em aplicativo do TCM. Disponível em:

<http://www.tcm.ce.gov.br/tcm-site/noticias/portal-da-transparencia-e-lancado-emaplicativo-do-tcm/>. Acesso em: 10 dez.2016. 